\title{
Lignin as a multifunctional photocatalyst for solar-powered biocatalytic oxyfunctionalization of $\mathrm{C}-\mathrm{H}$ bonds
}

\author{
Jinhyun Kim, ${ }^{[a]}$ Frank Hollmann, ${ }^{[b]}$ and Chan Beum Park*[a]

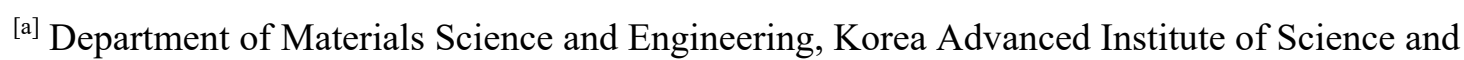 \\ Technology (KAIST), 335 Science Road, Daejeon 305-701, Republic of Korea; \\ ${ }^{[b]}$ Department of Biotechnology, Delft University of Technology, Van der Maasweg 9, 2629HZ Delft, \\ The Netherlands. *E-mail: parkcb@kaist.ac.kr
}

\section{Abstract}

Lignin is a key structural material in all terrestrial plants that is responsible for cell wall formation, water transportation, seed protection, and stress adaptation. Each year, pulp and paper industry produces approximately 50 million metric tons of lignin as waste, $95 \%$ of which is combusted or abandoned. Here, we report a new multifunctionality of lignin as a photocatalyst (e.g., synergistic formation of $\mathrm{H}_{2} \mathrm{O}_{2}$ formation through $\mathrm{O}_{2}$ reduction and $\mathrm{H}_{2} \mathrm{O}$ oxidation, use of $\mathrm{H}_{2} \mathrm{O}$ as an electron donor, and $\mathrm{OH}^{-}$-scavenging activity). Our spectroscopic and photoelectrochemical analyses reveal the photophysical characteristics (e.g., light absorption, charge separation/transfer) of lignin models [e.g., lignosulfonate (LS) and kraft lignin (KL)] and their electronic properties [HOMO-LUMO gap: $2.67 \mathrm{eV}(\mathrm{LS}), 2.95 \mathrm{eV}$ (KL), LUMO: -0.23 $\mathrm{V}_{\text {RHE }}(\mathrm{LS})$ and -0.26 $\mathrm{V}_{\text {RHE }}(\mathrm{KL}), \mathrm{HOMO}: 2.44 \mathrm{~V}_{\mathrm{RHE}}(\mathrm{LS})$ and 2.69 $\left.\mathrm{V}_{\text {RHE }}(\mathrm{KL})\right]$. We demonstrate lignin-sensitized redox chemistry, such as (i) $\mathrm{H}_{2} \mathrm{O}_{2}$ formation through $\mathrm{O}_{2}$ reduction using $\mathrm{H}_{2} \mathrm{O}$ as an electron donor and (ii) $\mathrm{O}_{2}$ evolution through $\mathrm{H}_{2} \mathrm{O}$ oxidation, under visible light. Furthermore, the integration of lignin and $\mathrm{H}_{2} \mathrm{O}_{2}$-dependent unspecific peroxygenases (UPOs) enables enantiospecific oxyfunctionalization reactions (e.g., benzylic hydroxylation, alkane hydroxylation, styrene epoxidation). Lignin photocatalysts solve existing issues (e.g., requirement of artificial electron donors, $\mathrm{H}_{2} \mathrm{O}_{2}$ - or $\mathrm{OH}^{-}$-driven inactivation of UPO) related to the sustainable activation of UPO. The lignin/UPO hybrid achieves a total turnover number of enzyme of 81070 , the highest value ever recorded for solar-powered biocatalytic 
1 oxyfunctionalization in photochemical platforms. This work demonstrates the propriety of 2 lignin in robust photocatalyst/biocatalyst hybrids for artificial photosynthesis.

3

4 Keywords: lignin, photobiocatalysis, artificial photosynthesis, redox biocatalysis, selective 5 oxyfunctionalization 
2 Selective oxyfunctionalization reactions of nonactivated $\mathrm{C}-\mathrm{H}$ bonds are the holy grail in

3 synthetic chemistry because they require the reorganization of kinetically inert $\mathrm{C}-\mathrm{H}$ bonds. ${ }^{1}$

4 Heme-thiolate enzymes have garnered much interest because of their high reactivity, selectivity,

5 and a broad substrate range., ${ }^{2,3}$ Nowadays, cytochrome P450 monooxygenases are used widely

6 as biocatalysts ${ }^{4}$ to oxyfunctionalize hydrocarbons, but they depend on complex electron

7 transport pathways, ${ }^{5}$ requiring one molecular oxygen and two electrons that are delivered by

8 redox equivalents [e.g., 1,4-dihydronicotinamide adenine dinucleotide or its phosphorylated

9 form, $\mathrm{NAD}(\mathrm{P}) \mathrm{H}]$. In contrast, unspecific peroxygenases (UPOs, IUBMB classification: EC

10 1.11.2.1) use hydrogen peroxide $\left(\mathrm{H}_{2} \mathrm{O}_{2}\right)$ only to generate the catalytically active oxoferryl-

11 heme (Compound I) through the peroxide shunt pathway, ${ }^{3,5}$ making UPOs a promising

12 alternative to P450 monooxygenases and chemical counterparts.

13 Nevertheless, UPOs suffer from the oxidative inactivation of their heme active sites in

14 the presence of elevated concentrations of $\mathrm{H}_{2} \mathrm{O}_{2} .{ }^{6}$ This instability has been addressed through

15 the use of additional redox catalysts ${ }^{3,4,7,8}$ that facilitate in situ $\mathrm{H}_{2} \mathrm{O}_{2}$ supply in adequate

16 concentrations. Most of these catalysts reduce $\mathrm{O}_{2}$ to $\mathrm{H}_{2} \mathrm{O}_{2}\left(\mathrm{O}_{2}+2 \mathrm{H}^{+}+2 \mathrm{e}^{-} \rightarrow \mathrm{H}_{2} \mathrm{O}_{2}\right)$ at the

17 expense of artificial electron donors (e.g., alcohol ${ }^{4}$, formate ${ }^{7,8}$ ) or cosubstrates (e.g., glucose ${ }^{3}$ ).

18 This necessity complicates the reaction schemes and causes serious issues, such as poor atom

19 economy (e.g., $16.03 \%$ for the glucose/glucose oxidase systems ${ }^{3}$ ) and the accumulation of 20 undesirable side products (e.g., gluconic acid ${ }^{4,9}$ ). The challenge can be circumvented if the

21 redox catalyst can use water as an electron donor and a cosubstrate in $\mathrm{O}_{2}$ reduction to $\mathrm{H}_{2} \mathrm{O}_{2}$ and

$22 \mathrm{H}_{2} \mathrm{O}$ oxidation to $\mathrm{H}_{2} \mathrm{O}_{2}$, respectively. This strategy is based on (i) water's role as a solvent in

23 UPO catalysis, (ii) its abundance $(55.55 \mathrm{M})$, (iii) the near-unity atom economy of $\mathrm{H}_{2} \mathrm{O}_{2}$

24 production $\left(94.44 \% ; 2 \mathrm{H}_{2} \mathrm{O} \rightarrow \mathrm{H}_{2} \mathrm{O}_{2}+2 \mathrm{H}^{+}+2 \mathrm{e}^{-}\right.$), and (iv) $\mathrm{O}_{2}$ molecules as a side product of 
water oxidation $\left(2 \mathrm{H}_{2} \mathrm{O} \rightarrow \mathrm{O}_{2}+4 \mathrm{H}^{+}+4 \mathrm{e}^{-}\right)^{10}$. Despite these merits, water oxidation catalysts have the disadvantage of producing reactive oxygen species, which is detrimental to UPOdriven catalysis. For example, cutting-edge photochemical systems ${ }^{8,9,11}$ oxidize $\mathrm{H}_{2} \mathrm{O}$ to hydroxyl radicals $\left(\mathrm{OH}^{*}\right)$ that inactivate UPOs.

Here, we report lignin as a multifunctional photocatalyst that accomplishes such challenging goals (i.e., in situ $\mathrm{H}_{2} \mathrm{O}_{2}$ formation through $\mathrm{O}_{2}$ reduction and $\mathrm{H}_{2} \mathrm{O}$ oxidation, use of $\mathrm{H}_{2} \mathrm{O}$ as an electron donor, and $\mathrm{OH}^{*}$-scavenging activity) for sustainable UPO catalysis under visible light (Fig. 1). Solar energy holds great promise as an abundant, sustainable, and clean resource of chemical potential ${ }^{12-15}$; hence, photocatalysts have been applied extensively for solar-to-chemical conversion (e.g., aliphatics production ${ }^{16,17}$, hydrogen evolution ${ }^{18,19}$, methanation ${ }^{20}$ ). Lignin — the second most earth-abundant biopolymer —is highly functionalized with various aromatic unit structures in lignocellulosic biomass. ${ }^{21,22}$ The pulp, paper, and biofuel industries generate lignin as waste with an annual production of around 50 million metric tons. ${ }^{23}$ However, $95 \%$ of lignin is abandoned or combusted ${ }^{23,24}$ in biorefinery processes because of its complex, irregular, and ill-defined chemical structure. ${ }^{21,23,25}$ Recently, lignin materials have been studied to (i) prepare value-added aromatics ${ }^{26}$ and (ii) use themselves as building blocks ${ }^{21}$ for energy and environmental applications.

Moving beyond these conventional approaches, we hypothesize that lignin polymers can perform photoredox reactions because they contain $\pi$-conjugated systems with redox moieties that most molecular photocatalysts share ${ }^{27,28}$; delocalized electrons in circular $\pi$ bonds can be photoexcited to energetically higher levels, causing them to participate in photoinduced electron transfer for solar-driven redox chemistry. Inspired by their molecular structures, we investigate lignin's electronic and photophysical properties and demonstrate lignin-sensitized $\mathrm{H}_{2} \mathrm{O}_{2}$ formation (through $\mathrm{O}_{2}$ reduction and $\mathrm{H}_{2} \mathrm{O}$ oxidation) and $\mathrm{O}_{2}$ evolution (through $\mathrm{H}_{2} \mathrm{O}$ oxidation) under visible light. This synergistic photoredox reaction is further combined with 
1 peroxygenase biocatalysis to accomplish the photoenzymatic oxidation of nonactivated $\mathrm{C}-\mathrm{H}$

2 bonds and thus synthesize enantiopure alcohols and epoxides [i.e., enantiomeric excess (ee) $>$

$399 \%$ ]. Furthermore, the lignin photocatalysts function as an antioxidant to suppress $\mathrm{OH}^{*}$ -

4 mediated UPO inactivation. This enables the lignin/peroxygenase system to achieve the

5 highest-ever-recorded longest reaction time and total turnover number of $130 \mathrm{~h}$ and 81070 ,

6 respectively, among solar-assisted biocatalytic oxyfunctionalization studies.

8 Results

$9 \quad$ Electronic and photophysical properties of lignins

10 We chose lignosulfonate (LS) and kraft lignin (KL) as our model lignin. These lignin 11 macromolecules are isolated from lignocellulosic biomass via sulfite and kraft pulping 12 processes, respectively. ${ }^{21}$ The different chemical treatments give LS and KL rather different 13 chemical and redox properties. To better understand the origin of lignin's photocatalytic 14 activity, we investigated the optical absorption property using ultraviolet-visible (UV-Vis) 15 spectroscopy. KL exhibited a stronger photoabsorption from UV to visible light region 16 compared with LS (Supplementary Fig. 1a). The energy gaps between the LS and KL's 17 highest occupied molecular orbital (HOMO) and the lowest unoccupied molecular orbital 18 (LUMO) were estimated to be $c a .2 .67$ and $2.95 \mathrm{eV}$, respectively, based on the absorption 19 analysis (Supplementary Figs. 1b and 1c). Next, we used ultraviolet photoelectron 20 spectroscopy to estimate the HOMO levels of the lignins. Note that the photoemission 21 spectroscopy is used widely to characterize the valence electronic states of organic materials. ${ }^{29}$

22 We found that LS and KL's HOMO levels were 2.44 and $2.69 \mathrm{~V}$ (vs. reversible hydrogen 23 electrode, RHE), respectively (Supplementary Fig. 2). Thus, the LUMO energies of LS and 
1 KL were calculated to be -0.23 and -0.26 VRHE, respectively, based on their HOMO-LUMO gaps (Fig. 2a).

The separation/recombination and transfer of photoexcited charge carriers are key

4 factors in photoredox reactions because the charge carriers must be delivered to adjacent

5 substrates. We found that KL exhibited more efficient charge separation than LS; according to

6 the photoluminescence spectra of LS and KL (Supplementary Fig. 3), the emission intensity

7 of KL was much lower than that of LS, which we attribute to slower charge recombination in

8 KL. Furthermore, KL exhibited better charge transfer ability than LS. According to our

9 chopped-light chronoamperometric analysis (Fig. 2b), the photocurrent of KL was 10 approximately four times higher than that of LS under visible light $(\lambda>400 \mathrm{~nm})$. This

11 photosensitization results from their HOMO-LUMO gaps in the visible range (Fig. 2a and

12 Supplementary Figs. 1b and 1c). The difference in the lignins' charge transport properties

13 were further supported by electrochemical impedance spectroscopic analysis; we measured the

14 charge transfer resistance of lignins using Nyquist plots, which were fitted to the Randles

15 circuit model. As shown in Fig. 2c, KL exhibited lower charge-transfer resistance than LS

16 under visible light. Furthermore, LS and KL were highly stable under visible light

17 (Supplementary Fig. 4), which contrasts with the rapid photobleaching of many common 18 photocatalysts. ${ }^{7,10}$

20 Lignin-sensitized reduction of $\mathrm{O}_{2}$ to $\mathrm{H}_{2} \mathrm{O}_{2}$ under visible light

21 Building on the electronic and photophysical properties of lignins, we investigated their

22 capability to photocatalytically reduce $\mathrm{O}_{2}$ to $\mathrm{H}_{2} \mathrm{O}_{2}$ because the reduction potential of $\mathrm{O}_{2} / \mathrm{H}_{2} \mathrm{O}_{2}$

23 [equation (1) $]^{30}$ is more positive than the lignins' LUMO levels (Fig. 2a).

24

$$
\mathrm{O}_{2}(\mathrm{aq})+2\left(\mathrm{H}^{+}+\mathrm{e}^{-}\right) \rightarrow \mathrm{H}_{2} \mathrm{O}_{2}(\mathrm{aq}), E_{\text {red }}=1.14 \mathrm{~V} \text { RHE }
$$


1 In addition to the thermodynamic requirement, the interaction between the electron acceptor

2 (e.g., dioxygen) and the donor (e.g., lignins) plays an important role in redox catalysis. Thus,

3 we used UV-Vis spectroscopy to examine the attractive interaction between $\mathrm{O}_{2}$ and the $\pi$ -

4 conjugated moieties of lignins. As shown in Supplementary Fig. 5, the absorbance of LS and

5 KL gradually increased with the $\mathrm{O}_{2}$ purging time. This result indicates that lone pair- $\pi$

6 interactions change $\pi-\pi^{*}$ electronic transitions ${ }^{31}$ of $\pi$-functionalities (e.g., phenoxy groups,

7 conjugated carbonyl groups) in lignin's monomeric phenylpropanes.

Having substantiated the favorable noncovalent interaction between the lignins and $\mathrm{O}_{2}$,

9 we exposed a lignin solution $\left(1 \mathrm{mg} \mathrm{mL}^{-1}\right)$ in an $\mathrm{O}_{2}$-enriched phosphate buffer $(\mathrm{KPi}, 100 \mathrm{mM}$, $10 \mathrm{pH}$ 7.0) to visible light from a solar simulator $(\lambda>400 \mathrm{~nm})$. Photoactivated LS and KL 11 gradually accumulated $\mathrm{H}_{2} \mathrm{O}_{2}$ at a rate of $79.92 \pm 19.35$ and $158.49 \pm 25.13 \mathrm{mM} \mathrm{g}_{\text {cat }}^{-1} \mathrm{~h}^{-1}$, respectively (Fig. 3a). We attribute KL's faster $\mathrm{H}_{2} \mathrm{O}_{2}$ production to its higher light absorption,

13 charge separation, and charge transfer (Supplementary Figs. 1a and 3 and Figs. 2 b and $2 c$ ).

14 When we irradiated the lignin solutions with monochromated light, the apparent quantum 15 yields of LS and KL decreased with the increasing wavelength of the incident light 16 (Supplementary Fig. 6); these action spectra of LS and KL were analogous to the lignins' 17 absorption spectra, indicating that photoactivation of LS and $\mathrm{KL}$ is the key step for $\mathrm{H}_{2} \mathrm{O}_{2}$ 18 formation. Control experiments in the absence of lignins or light resulted in a negligible $\mathrm{H}_{2} \mathrm{O}_{2}$ 19 production (Fig. 3a and Supplementary Fig. 7).

The reduction of $\mathrm{O}_{2}$ to $\mathrm{H}_{2} \mathrm{O}_{2}$ can proceed through (i) a two-step, single-electron 21 reduction (i.e., $\mathrm{O}_{2} \rightarrow \mathrm{O}_{2}^{\cdot-} \rightarrow \mathrm{H}_{2} \mathrm{O}_{2}$ ) or (ii) a one-step, two-electron reduction (i.e., $\mathrm{O}_{2} \rightarrow \mathrm{H}_{2} \mathrm{O}_{2}$ ) 22 route. ${ }^{32}$ To elucidate the pathway of lignin-sensitized $\mathrm{H}_{2} \mathrm{O}_{2}$ production, we analyzed the 23 formation of superoxide ions $\left(\mathrm{O}_{2}{ }^{--}\right)$using a nitroblue tetrazolium assay ${ }^{10}$ (Supplementary Fig. 24 8a). LS and $\mathrm{KL}$ photocatalysts produced $\mathrm{O}_{2}{ }^{--}$under visible light in an $\mathrm{O}_{2}$-enriched 25 environment, whereas a negligible amount of the ion was detected under $\mathrm{N}_{2}$-rich or dark 
1 conditions (Supplementary Fig. 8b). The addition of 1,4-benzoquinone $\left(\mathrm{O}_{2}{ }^{\bullet-} \text { scavenger }\right)^{33}$ into

2 an $\mathrm{O}_{2}$-purged lignin solution decreased the rate of $\mathrm{H}_{2} \mathrm{O}_{2}$ formation by $\mathrm{LS}$ and $\mathrm{KL}$

3 photocatalysts (Fig. 3b, left panel), which supports the two-step reduction of $\mathrm{O}_{2}$ to $\mathrm{H}_{2} \mathrm{O}_{2}$.

5 Photocatalytic $\mathrm{H}_{2} \mathrm{O}$ oxidation to $\mathrm{H}_{2} \mathrm{O}_{2}$ and $\mathrm{O}_{2}$

6 We paid particular attention to the absence of artificial electron donors for the lignin-catalyzed 7 production of $\mathrm{H}_{2} \mathrm{O}_{2}$ because the incomplete depression of $\mathrm{H}_{2} \mathrm{O}_{2}$ formation (Fig. 3b, left panel)

8 can originate from the oxidation of the $\mathrm{H}_{2} \mathrm{O}$ solvent to $\mathrm{H}_{2} \mathrm{O}_{2}$. This motivated us to evaluate the 9 capability of photoactive lignins to oxidize $\mathrm{H}_{2} \mathrm{O}$. Note that lignin photoexcitation enables 10 thermodynamically favorable oxidation of $\mathrm{H}_{2} \mathrm{O}$ to $\mathrm{H}_{2} \mathrm{O}_{2}$ [equation (2)] ${ }^{10}$ because the HOMO 11 levels of LS and KL are more positive than the oxidation potential of $\mathrm{H}_{2} \mathrm{O}$ to $\mathrm{H}_{2} \mathrm{O}_{2}$ (Fig. 2a).

$$
2 \mathrm{H}_{2} \mathrm{O}(\mathrm{l}) \rightarrow \mathrm{H}_{2} \mathrm{O}_{2}(\mathrm{aq})+2\left(\mathrm{H}^{+}+\mathrm{e}^{-}\right), E_{\mathrm{ox}}=1.76 \mathrm{~V} \text { RHE }
$$

13 To exclude $\mathrm{H}_{2} \mathrm{O}_{2}$ production via $\mathrm{O}_{2}$ reduction reaction, we purged $\mathrm{N}_{2}$ gas into a lignin solution 14 before and during photocatalysis. As shown in Fig. 3b (right panel), the rate of $\mathrm{H}_{2} \mathrm{O}_{2}$ 15 formation decreased to 24.93 and $66.44 \mathrm{mM} \mathrm{g}_{\mathrm{cat}}{ }^{-1} \mathrm{~h}^{-1}$ for LS and KL, respectively. This result 16 indicates that water oxidation is another photocatalytic pathway for $\mathrm{H}_{2} \mathrm{O}_{2}$ production on LS and

17 KL. The rates were almost identical to those observed in the presence of 1,4-benzoquinone $18\left(\mathrm{O}_{2}{ }^{\cdot-}\right.$ scavenger) under $\mathrm{O}_{2}$-enriched conditions (Fig. 3b, left panel; statistically insignificant 19 difference according to one-way analysis of variance), which implies that one-step reduction of $20 \mathrm{O}_{2}$ to $\mathrm{H}_{2} \mathrm{O}_{2}$ rarely occurs. Furthermore, we also confirmed the lignin-catalyzed formation of $\mathrm{O}_{2}$ 21 [equation (3) ${ }^{10}$ and Supplementary Fig. 9] using head-space gas chromatography.

$$
2 \mathrm{H}_{2} \mathrm{O}(\mathrm{l}) \rightarrow \mathrm{O}_{2}(\mathrm{~g})+4\left(\mathrm{H}^{+}+\mathrm{e}^{-}\right), E_{\mathrm{ox}}=1.23 \mathrm{VRHE}
$$


$1 \mathrm{O}_{2}$ formation is thermodynamically favorable because $E_{\mathrm{ox}}\left(\mathrm{O}_{2} / \mathrm{H}_{2} \mathrm{O}\right)$ is less positive than the

2 HOMO levels of LS and KL. Taken together, the lignin photocatalysts serve two functions: (i)

3 the reduction of $\mathrm{O}_{2}$ to $\mathrm{H}_{2} \mathrm{O}_{2}$ and (ii) the oxidation of $\mathrm{H}_{2} \mathrm{O}$ to $\mathrm{H}_{2} \mathrm{O}_{2}$ and $\mathrm{O}_{2}$.

Based on the extensively accepted mechanism of photoredox catalysis, ${ }^{27,34}$ we propose

5 that a possible process for $\mathrm{O}_{2}$ reduction and $\mathrm{H}_{2} \mathrm{O}$ oxidation using lignins involve a combination

6 of reductive and oxidative quenching cycles of lignin photocatalysts, as depicted in Fig. 3c.

7 Light absorption of lignin causes it to become a photoactivated state, [lignin] ${ }^{*}$, which is both a

8 stronger oxidant and a stronger reductant than its corresponding ground state. In a reductive

9 quenching pathway, [lignin] ${ }^{*}$ oxidizes $\mathrm{H}_{2} \mathrm{O}$ to $\mathrm{H}_{2} \mathrm{O}_{2}$ or $\mathrm{O}_{2}$ and becomes the reduced catalyst, 10 [lignin $]^{--}$. This state reduces $\mathrm{O}_{2}$ to $\mathrm{H}_{2} \mathrm{O}_{2}$ and returns to its original state. In an oxidative quenching process, the oxidized catalyst, [lignin] ${ }^{\circ+}$, is formed through $\mathrm{O}_{2}$ reduction, which then reverts to its original state via $\mathrm{H}_{2} \mathrm{O}$ oxidation. The HOMO and LUMO levels of LS and KL

13 make $[\mathrm{LS}]^{*}$ and $[\mathrm{KL}]^{*}$ thermodynamically favorable for the photocatalytic production of $\mathrm{H}_{2} \mathrm{O}_{2}$

14 and $\mathrm{O}_{2}$ through $\mathrm{O}_{2}$ reduction and $\mathrm{H}_{2} \mathrm{O}$ oxidation.

Enantioselective photoenzymatic oxyfunctionalization reactions

17 Having substantiated in situ $\mathrm{H}_{2} \mathrm{O}_{2}$ generation by the lignin photocatalysts, we established

18 photobiocatalytic oxyfunctionalization reaction by coupling lignin-driven photocatalysis with

19 peroxygenase-mediated biocatalysis in a one-pot process. We chose the UPO from Agrocybe

20 aegerita, which was expressed recombinantly in Pichia pastoris (rAaeUPO) ${ }^{3}$ because of its

21 versatility ${ }^{33}$ and high activity toward inert $\mathrm{C}-\mathrm{H}$ bonds ${ }^{35}$. We tested ethylbenzene as a model

22 substrate because the hydroxylation of a methylene $\mathrm{C}-\mathrm{H}$ bond adjacent to oxidatively more

23 labile $\pi$-functionality is very challenging ${ }^{36}$. As shown in Supplementary Fig. 10, LS/rAaeUPO

24 and KL/rAaeUPO systems converted ethylbenzene to $(R)$-1-phenylethanol enantiospecifically 
$1 \quad(>99 \%$ ee $)$ under visible light $(\lambda>400 \mathrm{~nm})$. Noteworthy, the stereo- and chemoselectivity of

2 the overall reaction was very high, in contrast to previous photoenzymatic reactions ${ }^{3,4,8}$; the

3 previous studies reported the non-enzymatic oxidation of the substrate and the alcohol product

4 to a racemic product and overoxidation product acetophenone, respectively. The omission of

5 lignin, light, or substrate led to a negligible yield of 1-phenylethanol (Supplementary Fig. 10)

6 because of the imperceptible formation of $\mathrm{H}_{2} \mathrm{O}_{2}$ under the depleted conditions (Fig. 3a and

7 Supplementary Fig. 7). However, the photobiocatalytic reaction occurred under $\mathrm{O}_{2}$-depleted

8 conditions because of the in situ $\mathrm{H}_{2} \mathrm{O}$ oxidation to $\mathrm{H}_{2} \mathrm{O}_{2}$ (Fig. 3b and Supplementary Fig. 10).

9 We investigated the kinetics of the photoenzymatic reaction with respect to lignin

10 concentration and photon flux. As shown in Supplementary Fig. 11a, the turnover frequencies

11 of $\mathrm{r}$ AaeUPO (TOF $\mathrm{T}_{\mathrm{A} a e \mathrm{UPO}}$ ) were saturated with lignin concentration at over $8 \mathrm{mg} \mathrm{mL}^{-1}$,

12 indicating that $\mathrm{H}_{2} \mathrm{O}_{2}$ formation is a rate-limiting step. When we varied photon flux at a fixed

13 lignin concentration $\left(8 \mathrm{mg} \mathrm{mL}^{-1}\right)$, the $\mathrm{TOF}_{\mathrm{r} A a e \mathrm{UPO}}$ of LS/rAaeUPO became larger than that of

$14 \mathrm{KL} / \mathrm{r}$ AaeUPO at over $1.16 \mu \mathrm{E} \mathrm{cm}^{-2} \mathrm{~s}^{-1}$ (Supplementary Fig. 11b). We attribute the result to

15 the higher optical transparency of LS compared with KL (Supplementary Fig. 12); the self-

16 shading effect of KL decreased light penetration, making some KL photocatalysts inactive in a 17 reaction solution. The hydroxylation reaction exhibited a saturated $\mathrm{TOF}_{\mathrm{r} A a e \mathrm{UPO}}$ at over $1.74 \mu \mathrm{E}$ $18 \mathrm{~cm}^{-2} \mathrm{~s}^{-1}$.

We further conducted a long-term photobiocatalytic oxyfunctionalization reaction

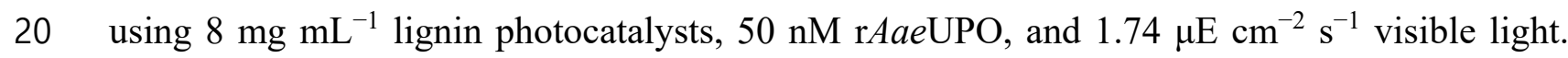
21 The LS/rAaeUPO and KL/rAaeUPO hybrids produced enantiopure products for at least $130 \mathrm{~h}$ 22 (Supplementary Fig. 13), thereby recording total turnover numbers of r $A a e U P O\left(\mathrm{TTN}_{\mathrm{r} A a e \mathrm{UPO})}\right.$ 23 of 81070 and 72552, respectively (Table 1, entry 1). Furthermore, the lignin/rAaeUPO 24 couples exhibited applicability to other enantiospecific oxyfunctionalization reactions; as 25 summarized in Table 1, the light-driven enzymatic systems achieved (i) the hydroxylation of 
1 propylbenzene, tetralin, and cyclohexane (entries 2-4) and (ii) the epoxidation of cis- $\beta$ -

2 methylstyrene (entry 5).

The robustness of the lignin/rAaeUPO hybrids is much better than those of other water

4 oxidation catalysts/UPO systems ${ }^{8,9,11}$; these reported abiotic catalysts generate hydroxyl

5 radicals to oxidatively inactivate UPOs, thus ceasing their biocatalytic reactions within $35 \mathrm{~h}$.

6 Thus, we hypothesized that water-oxidizing LS and KL energy materials do not produce

7 hydroxyl radicals. We analyzed the formation of $\mathrm{OH}^{\bullet}$ using a terephthalic acid assay ${ }^{37}$.

8 Photoactivated LS and KL produced a negligible amount of the radical under visible light

9 (Supplementary Fig. 14) although they exhibit thermodynamic favorability of $\mathrm{OH}^{*}$ formation 10 via two pathways [i.e., $\mathrm{H}_{2} \mathrm{O}$ oxidation (equation (4)) and $\mathrm{H}_{2} \mathrm{O}_{2}$ reduction? (equation (5))].

$$
\mathrm{H}_{2} \mathrm{O}(\mathrm{l}) \rightarrow \mathrm{OH}^{\cdot}(\mathrm{aq})+\left(\mathrm{H}^{+}+\mathrm{e}^{-}\right), E_{\mathrm{ox}}=2.38 \mathrm{~V}_{\mathrm{RHE}}
$$

$$
\mathrm{H}_{2} \mathrm{O}_{2}(\mathrm{aq})+\mathrm{e}^{-} \rightarrow \mathrm{OH}^{\bullet}(\mathrm{aq})+\mathrm{OH}^{-}, E_{\text {red }}=0.79 \mathrm{~V}_{\mathrm{RHE}}
$$

13 This result motivated us to investigate the $\mathrm{OH}^{-}$-scavenging activities of lignin photocatalysts.

14 We produced hydroxyl radicals using a nanostructured hematite electrode $\left(\alpha-\mathrm{Fe}_{2} \mathrm{O}_{3}\right.$;

15 Supplementary Fig. 15) and detected the radicals in the absence and presence of 16 photoactivated lignins. As shown in Supplementary Fig. 16, the $\alpha-\mathrm{Fe}_{2} \mathrm{O}_{3}$ photoanode formed $17 \mathrm{OH}^{\bullet}$ radicals in an $\mathrm{O}_{2}$-purged $\mathrm{KPi}$ buffer at $0.622 \mathrm{VRHE}(0 \mathrm{~V} \mathrm{Ag} / \mathrm{AgCl})$ under visible light (see the 18 detailed explanations in the figure legend). In contrast, the radical was not detected when lignin 19 photocatalysts were extant in the buffer, which indicates the antioxidant properties of lignin 20 materials. 
2 The present work identifies the capability of lignin as a non-metallic photocatalyst. Through

3 spectroscopic and photoelectrochemical analyses, we substantiated that LS and KL absorb

4 visible light [HOMO-LUMO gap (in eV): 2.67 (LS) and 2.95 (KL)] to promote electronic

5 transition to energetically higher levels [HOMO (in V $\mathrm{V}_{\mathrm{RHE}}$ ): 2.44 (LS) and 2.69 (KL), LUMO

6 (VRHE): -0.23 (LS) and -0.26 (KL)]. Based on these thermodynamic indices of lignin

7 photocatalysts, we unveiled lignin-sensitized (i) $\mathrm{O}_{2}$ reduction to $\mathrm{H}_{2} \mathrm{O}_{2}$ and (ii) $\mathrm{H}_{2} \mathrm{O}$ oxidation to

$8 \mathrm{H}_{2} \mathrm{O}_{2}$ and $\mathrm{O}_{2}$ under solar irradiation $(\lambda>400 \mathrm{~nm}) . \mathrm{H}_{2} \mathrm{O}$ is the most desirable electron donor in

9 aqueous redox chemistry because it is abundant and biocompatible, and simplifies reaction

10 schemes; the thermodynamic favorability of lignin photocatalysts for $\mathrm{H}_{2} \mathrm{O}$ oxidation makes

11 them distinct from many other photocatalysts ${ }^{7,8,32}$ that rely on artificial electron suppliers (e.g.,

12 formic acid, primary/secondary alcohol). In addition, lignin oxidizes $\mathrm{H}_{2} \mathrm{O}$ to $\mathrm{H}_{2} \mathrm{O}_{2}$ and $\mathrm{O}_{2}$; this

13 builds up local concentrations of oxygen in the vicinity of lignin photocatalysts, which can

14 escalate the rate of $\mathrm{O}_{2}$ reduction to $\mathrm{H}_{2} \mathrm{O}_{2}$. The dual production of $\mathrm{H}_{2} \mathrm{O}_{2}$ and $\mathrm{O}_{2}$ via the $\mathrm{H}_{2} \mathrm{O}$

15 oxidation route is demonstrated for the first time in the field of photocatalysis.

Furthermore, this study reports UPO-catalyzed enantioselective oxyfunctionalization

17 reactions (e.g., benzylic hydroxylation, alkane hydroxylation, styrene epoxidation) through

18 lignin-driven generation of $\mathrm{H}_{2} \mathrm{O}_{2}$ in situ under visible light. Among photoenzymatic systems $\mathrm{s}^{3,8}$

19 using visible light and $\mathrm{H}_{2} \mathrm{O}$, lignin/UPO hybrids are more apposite in the production of 20 enantiopure alcohols and epoxides (i.e., $>99 \%$ ee). Furthermore, lignin's phenol-based 21 monomeric units exhibit an antioxidative function, ${ }^{21,38}$ which addresses the inactivation issue

22 of UPOs against $\mathrm{OH}^{*}$ radicals; this property is a departure from $\mathrm{OH}^{*}$-generating behaviors of

23 water oxidation catalysts ${ }^{8,9,11}$ that halt UPO-mediated biotransformations. Thus, lignin/UPO

24 combinations compare favorably with cutting-edge photoenzymatic systems that use rAaeUPO 
1 under visible light (Fig. 4). Photoactive nanomaterials $\mathrm{s}^{3,4,8}$ and $\pi$-conjugated acridine

2 derivatives ${ }^{7}$ (e.g., gold-loaded $\mathrm{TiO}_{2}$, graphitic $\mathrm{C}_{3} \mathrm{~N}_{4}$, methylene blue, phenosafranine, flavin

3 mononucleotide) require artificial electron donors (e.g., methanol, formate, in situ regenerated

4 NADH) to achieve meaningful TTNs (10879 to 71000). The $\mathrm{TTN}_{\mathrm{r} A a e \mathrm{UPO}}$ of lignin

5 photocatalysts was the highest even at the expense of $\mathrm{H}_{2} \mathrm{O}$ as a clean and desirable electron

6 donor. Furthermore, the catalytic performance (e.g., ee, catalytic turnover) of rAaeUPO

7 outweighs those of chemical catalysts and well-established P450 monooxygenases

8 (Supplementary Table 2). Future challenges to enhancing enzymatic productivity would be (i)

9 the design of a biphasic aqueous/organic system to increase the concentration of hydrophobic

10 substrates and (ii) the conjugation of lignin with redox mediators to boost $\mathrm{H}_{2} \mathrm{O}_{2}$ formation

11 based on energy level matching.

12 In conclusion, the current work substantiates the multifunctional role of lignins-

13 synergistic $\mathrm{H}_{2} \mathrm{O}_{2}$ formation, $\mathrm{H}_{2} \mathrm{O}$ oxidation to $\mathrm{O}_{2}$, no necessity for artificial electron donors,

14 and $\mathrm{OH}^{\circ}$-scavenging activity —in a cascade process combining lignin photocatalysis and UPO

15 biocatalysis. Currently, lignin has been received as a waste and combusted in refinery

16 processes; however, shining light on lignin renders it productive in solar-to-chemical

17 conversion. The renewable biopolymers absorb visible light to generate $\mathrm{H}_{2} \mathrm{O}_{2}$ and $\mathrm{O}_{2}$ through

$18 \mathrm{O}_{2}$ reduction and $\mathrm{H}_{2} \mathrm{O}$ oxidation without requiring artificial electron donors. Furthermore, the

19 enantiospecific oxyfunctionalization of inert $\mathrm{C}-\mathrm{H}$ bonds $-\mathrm{a}$ dream reaction in synthetic

20 chemistry - is realized through the merger of lignin photocatalysts and peroxygenases.

21 Lignin's radical scavenging activities play a role in the protection of UPOs from $\mathrm{OH}^{*}$-driven

22 inactivation, conducing to the new benchmark ( $\mathrm{TTN}_{\mathrm{r} A a e \mathrm{UPO}}: 81070,>99 \%$ ee). Overall, this

23 work establishes lignin as an energy conversion material for producing fuels and chemicals,

24 presenting an example of waste-to-wealth conversion. 


\section{Experimental procedures}

\section{Chemicals and materials}

3 Hydrogen peroxide were purchased from Junsei Chemical Co., Ltd. (Tokyo, Japan). Potassium

4 phosphate monobasic and potassium phosphate dibasic were bought from Samchun Chemical

5 Co., Ltd. (Seoul, Korea). Lignosulfonic acid sodium salt, lignin (alkali), peroxidase from

6 horseradish, nitrotetrazolium blue chloride, 2,2'-azino-bis(3-ethylbenzothiazoline-6-sulfonic

7 acid) diammonium salt, magnesium sulfate, ethyl acetate, 1-octanol, ethylbenzene, $(R)-1$ -

8 phenylethanol, (S)-1-phenylethanol, acetophenone, iron(III) chloride hexahydrate, and sodium

9 nitrate were purchased from Sigma-Aldrich (St. Louis, MO, USA). $\mathrm{O}_{2}$ and $\mathrm{N}_{2}$ gases (purity: 10 99.999\%) were bought from Special Gas Co. (Daejeon, Korea). We used type 1 ultrapure water $11(18 \mathrm{M} \Omega \mathrm{cm})$ from a Direct-Q ${ }^{\circledR} 5 \mathrm{UV}$ ultrapure water purification system (Millipore Corp., 12 USA). A recombinant unspecific peroxygenase from Agrocybe aegerita (rAaeUPO) was 13 prepared as described previously ${ }^{8,9}$.

\section{Lignin characterization}

16 We recorded ultraviolet-visible spectra using a V-650 UV-Vis absorption spectrophotometer

17 (JASCO Inc., Japan). Photoluminescence spectra were obtained using a RF-5301PC 18 spectrofluorophotometer (Shimadzu Inc., Japan). Ultraviolet photoelectron spectra were 19 recorded using a Sigma Probe (Thermo VG Scientific, United Kingdom) with a photon energy 20 of $21.2 \mathrm{eV}$ (He I radiation). To make a sample for the photoelectron spectroscopic analysis, we 21 drop-casted a lignin solution $\left(80 \mathrm{mg} \mathrm{mL}^{-1}\right)$ on a fluorine-doped tin oxide (FTO) glass four 22 times and dried it at ambient condition. We employed a potentiostat/galvanostat (WMPG 1000, 23 WonATech Co., Korea) or impedance analyzer (ZIVE SP1, WonATech Co., Korea) to perform 24 photoelectrochemical analyses of lignin photocatalysts in a three-electrode configuration [a 
1 FTO glass (working electrode, geometrical surface area: $2.52 \mathrm{~cm}^{2}$ ), $\mathrm{Ag} / \mathrm{AgCl}$ electrode

2 (reference electrode, $3 \mathrm{M} \mathrm{NaCl}$ ), and a stainless steel (counter electrode)]. An electrolyte

3 solution was a potassium phosphate buffer $(\mathrm{KPi}, 100 \mathrm{mM}, \mathrm{pH} 7.0)$ containing $1 \mathrm{mg} \mathrm{mL}^{-1}$

4 lignosulfonate or kraft lignin. A solar-simulated light source was a xenon lamp (Newport Co.,

5 USA) equipped with an infrared water filter and $400 \mathrm{~nm}$ cut-on optical filter.

\section{Lignin-sensitized formation of $\mathrm{H}_{2} \mathrm{O}_{2}$}

8 The amount of $\mathrm{H}_{2} \mathrm{O}_{2}$ formed by lignin photocatalysts was determined spectrophotometrically 9 using 2,2'-azino-bis(3-ethylbenzothiazoline-6-sulfonic acid) (ABTS) assay. We dissolved 10 lignin in a KPi buffer (100 mM, pH 7.0, $2.0 \mathrm{~mL})$. We used a xenon lamp (equipped with an 11 infrared water filter and $400 \mathrm{~nm}$ longpass filter) to irradiate the sample at $298.15 \mathrm{~K}$. The 12 temperature was maintained using a water bath. The reaction sample $(0.05 \mathrm{~mL})$ was mixed 13 with a colorimetric reagent solution [2.5 $\mathrm{U}$ horseradish peroxidase and $2 \mathrm{mM}$ ABTS in a 14 phosphate solution $(0.95 \mathrm{~mL}, 100 \mathrm{mM}, \mathrm{pH} 5.0)]$. The absorbance of the mixture was monitored 15 at $420 \mathrm{~nm}$ using a V-650 UV-Vis absorption spectrophotometer (JASCO Inc., Japan). When 16 we obtained action spectra of lignin photocatalysts, the incident light was monochromated 17 using a 74004 Cornerstone ${ }^{\mathrm{TM}} 1301 / 8 \mathrm{~m}$ monochromator (Newport Co., USA).

NBT and TA assays

20 We used nitroblue tetrazolium (NBT) and terephthalic acid (TA) assays to detect superoxide 21 ions $\left(\mathrm{O}_{2}{ }^{\cdot-}\right)$ and hydroxyl radicals $\left(\mathrm{OH}^{*}\right)$, respectively. ${ }^{33}$ We added $10 \mu \mathrm{M}$ NBT or $300 \mu \mathrm{M}$ TA 22 in a lignin-containing reaction solution. This reaction solution was irradiated with solar-

23 simulated visible light from a xenon lamp equipped with a $400 \mathrm{~nm}$ cut-off filter (Newport Co., 
1 USA). After lignin-driven photocatalysis, we monitored a change in the absorbance at $560 \mathrm{~nm}$

2 and fluorescence intensity at $430 \mathrm{~nm}\left(\lambda_{\mathrm{ex}}=315 \mathrm{~nm}\right)$ to detect NBT formazan and 2-

3 hydroxyterephthalic acid (HTA), respectively.

\section{$5 \quad \mathbf{O}_{2}$ quantification}

6 To estimate the amount of $\mathrm{O}_{2}$ produced by lignin photocatalysts, $1 \mathrm{mg} \mathrm{mL} \mathrm{m}^{-1}$ lignin was

7 dissolved in a $\mathrm{N}_{2}$-purged $\mathrm{KPi}$ buffer $(100 \mathrm{mM}$, pH 7.0, $30 \mathrm{~mL})$. Because the reaction solution

8 was placed and sealed in an airtight chamber (volume: $50 \mathrm{~mL}$ ), we did not purge $\mathrm{N}_{2}$ gas (purity:

9 99.999\%) during photocatalytic reactions; otherwise, the chamber would have burst because of

10 excess internal pressure. The solution was exposed to visible light $(\lambda>400 \mathrm{~nm})$ from a xenon

11 lamp (Newport Co., USA) at $298.15 \mathrm{~K}$. The $\mathrm{O}_{2}$ molecules in the headspace were quantified

12 using an in situ gas chromatography (Micro GC fusion, INFICON Inc., USA) equipped with a

13 Molsieve 5A column and a micro thermal conductivity detector.

\section{Photobiocatalytic reaction and analysis}

16 We prepared a reaction sample by dissolving lignin, rAaeUPO, and substrate in a KPi solution

17 (100 mM, pH 7.0, $2.0 \mathrm{~mL})$ in an Eppendorf tube (SPL Life Sciences Co., Korea). The tube was

18 immersed in a water bath to maintain a reaction temperature at $298.15 \mathrm{~K}$ and irradiated with a

19 xenon lamp $(\lambda>400 \mathrm{~nm})$ to promote biocatalytic oxyfunctionalization reactions. When we

20 investigated the kinetics of photoenzymatic reactions, $\mathrm{O}_{2}$ gas (purity: 99.999\%) was purged

21 into reaction solutions (before and during the reactions) to make $\mathrm{O}_{2}$ an excess reactant.

22 However, we did not bubble $\mathrm{O}_{2}$ gas during long-term reactions because lignin photocatalysts

23 formed $\mathrm{H}_{2} \mathrm{O}_{2}$ via $\mathrm{H}_{2} \mathrm{O}$ oxidation reaction. $10 \mathrm{mM}$ substrate was added every $48 \mathrm{~h}$ to 
compensate for the high volatility of the substrate. After the photoenzymatic reactions, we extracted oxyfunctionalized products using ethyl acetate, dried them over $\mathrm{MgSO}_{4}$, and

3 quantified them using a 7890A gas chromatograph (Agilent Technologies, USA) equipped 4 with a flame ionization detector and a CP-Chirasil-Dex CB column $(25 \mathrm{~m} \times 0.32 \mathrm{~mm} \times 0.25$

$5 \mu \mathrm{m})$. Detailed oven temperature programs are tabulated in Supplementary Table 1. The 6 enantiomeric excess (ee), turnover frequency (TOF), and total turnover number (TTN) were 7 calculated using the following equations [equations (6), (7), and (8)]:

$$
e e(\%)=\frac{\mid \text { Moles of an enantiomer }- \text { Moles of the other enantiomer } \mid}{\text { Total moles of product }} \times 100
$$

$$
\operatorname{TOF}_{\mathrm{r} A a e \mathrm{UPO}}\left(\mathrm{h}^{-1}\right)=\frac{[\text { Product }]}{[\mathrm{r} \text { AaeUPO }] \times \text { Time }}
$$

$$
\mathrm{TTN}_{\mathrm{r} A a e \mathrm{UPO}}=\frac{\text { Maximum [Product }] \text { at a given time }}{[\mathrm{r} \text { AaeUPO }]}
$$

\section{Synthesis and characterization of hematite nanostructure}

13 We synthesized a hematite photoanode via solution-based processing and high temperature

14 annealing as reported previously ${ }^{39}$. We rinsed a FTO glass with acetone, isopropyl alcohol, and

15 deionized water. The glass was immersed in a precursor solution $\left(150 \mathrm{mM} \mathrm{FeCl}_{3} \cdot 6 \mathrm{H}_{2} \mathrm{O}\right.$ and

$161 \mathrm{M} \mathrm{NaNO}_{3}$ ) and heated in a Lindberg/Blue $\mathrm{M}$ muffle furnace (Fisher Scientific Co., USA) at

$17100{ }^{\circ} \mathrm{C}$ for $6 \mathrm{~h}$. Subsequently, we annealed the electrode at $800^{\circ} \mathrm{C}$ for $20 \mathrm{~min}$. The morphology

18 of a hematite material was examined using a S-4800 field-emission microscope (Hitachi High-

19 technologies Co., Japan). The crystallinity of a hematite film was examined using an Ultima IV

20 X-ray diffractometer (Rigaku Co., Japan) at KAIST Analysis center for Research

21 Advancement (KARA). The element identification of a hematite surface was conducted using 

an ESCALAB 250Xi X-ray photoelectron spectrometer (Thermo Scientific., USA) at KARA.

2 The light absorption capability of a hematite material was explored using a SolidSpec-3700

3 UV-VIS-NIR Spectrophotometer (Shimadzu Corp., Japan).

4

\section{$5 \quad$ Antioxidant property of lignin materials}

6 We carried out a photoelectrochemical reaction in a three-electrode configuration [working

7 electrode: $\alpha-\mathrm{Fe}_{2} \mathrm{O}_{3}$ (geometrical surface area: $2.5 \mathrm{~cm}^{2}$ ), reference electrode: $\mathrm{Ag} / \mathrm{AgCl}(3 \mathrm{M}$

$8 \mathrm{NaCl}$ ), counter electrode: stainless steel]. These three electrodes are immersed in an $\mathrm{O}_{2}$-purged

9 KPi buffer (100 mM, pH 7.0) containing 0.3 mM TA with/without lignin energy materials (e.g., 10 kraft lignin, lignosulfonate). We conducted controlled potential photoelectrocatalysis at 0 $11 \mathrm{~V}_{\mathrm{Ag} / \mathrm{AgCl}}\left(0.622 \mathrm{~V}_{\mathrm{RHE}}\right)$ under solar-simulated visible light $(\lambda>400 \mathrm{~nm}$, photon flux: $1.74 \mu \mathrm{E}$ $12 \mathrm{~cm}^{-2} \mathrm{~s}^{-1}$ ) to form hydroxyl radicals. Note that the lignin was also irradiated with the visible 13 light. After catalytic reactions, we measured the fluorescence intensity of the electrolyte 14 solution at $430 \mathrm{~nm}\left(\lambda_{\mathrm{ex}}=315 \mathrm{~nm}\right)$ to detect HTA.

\section{Conflicts of interest}

17 The authors declare no competing interests.

\section{Acknowledgements}

20 This work was supported by the National Research Foundation (NRF) via the Creative

21 Research Initiative Center (grant no. NRF-2015R1A3A2066191) and the Global Ph.D.

22 Fellowship Program (grant no. NRF-2019H1A2A1075810), Republic of Korea. The authors 
would like to thank Gihun Jung from Prof. Byungha Shin's group (Korea Advanced Institute of

2 Science and Technology) for permitting to use an in situ gas chromatograph.

\section{Author contributions}

5 J.K. and C.B.P. conceived and designed the research. C.B.P. supervised the research. J.K.

6 performed the experimental works and analyzed the results. F.H. provided biocatalysts. All 7 authors co-wrote the manuscript.

\section{References}

101 Kille, S., Zilly, F. E., Acevedo, J. P. \& Reetz, M. T. Regio- and stereoselectivity of P45011 catalysed hydroxylation of steroids controlled by laboratory evolution. Nat. Chem. 3, 738-743 12 (2011).

132 Gumulya, Y. et al. Engineering highly functional thermostable proteins using ancestral 14 sequence reconstruction. Nat. Catal. 1, 878-888 (2018).

153 Zhang, W. et al. Selective aerobic oxidation reactions using a combination of photocatalytic 16 water oxidation and enzymatic oxyfunctionalizations. Nat. Catal. 1, 55-62 (2018).

174 Zhang, W. et al. Selective Activation of $\mathrm{C}-\mathrm{H}$ Bonds in a Cascade Process Combining 18 Photochemistry and Biocatalysis. Angew. Chem. Int. Ed. 56, 15451-15455 (2017).

195 Lee, S. H., Choi, D. S., Kuk, S. K. \& Park, C. B. Photobiocatalysis: Activating Redox Enzymes 20 by Direct or Indirect Transfer of Photoinduced Electrons. Angew. Chem. Int. Ed. 57, 7958-7985 $21 \quad$ (2018).

226 Völler, J.-S. Enzymatic $\mathrm{H}_{2} \mathrm{O}_{2}$ for biocatalysis. Nat. Catal. 2, 375-375 (2019).

237 Willot, S. J. P. et al. Expanding the Spectrum of Light-Driven Peroxygenase Reactions. ACS 24 Catal. 9, 890-894 (2019).

258 van Schie, M. M. C. H. et al. Cascading $\mathrm{g}_{-} \mathrm{C}_{3} \mathrm{~N}_{4}$ and Peroxygenases for Selective 26 Oxyfunctionalization Reactions. ACS Catal. 9, 7409-7417 (2019).

279 Choi, D. S. et al. Bias-Free In Situ $\mathrm{H}_{2} \mathrm{O}_{2}$ Generation in a Photovoltaic-Photoelectrochemical 28 Tandem Cell for Biocatalytic Oxyfunctionalization. ACS Catal. 9, 10562-10566 (2019). 
10 Kim, J. et al. Nicotinamide adenine dinucleotide as a photocatalyst. Sci. Adv. 5, eaax0501 2 (2019).

311 Choi, D. S., Kim, J., Hollmann, F. \& Park, C. B. Solar-Assisted eBiorefinery: Photoelectrochemical Pairing of Oxyfunctionalization and Hydrogenation Reactions. Angew. Chem. Int. Ed., doi:10.1002/anie.202006893 (2020).

$\mathrm{Kim}$, J. et al. Robust $\mathrm{FeOOH} / \mathrm{BiVO} 4 / \mathrm{Cu}(\mathrm{In}, \mathrm{Ga}) \mathrm{Se}_{2}$ tandem structure for solar-powered biocatalytic $\mathrm{CO}_{2}$ reduction. J. Mater. Chem. A 8, 8496-8502 (2020). Kuk, S. K. et al. $\mathrm{CO}_{2}$-Reductive, Copper Oxide-Based Photobiocathode for Z-Scheme SemiArtificial Leaf Structure. ChemSusChem 13, 2940-2944 (2020).

Lee, Y. W. et al. Unbiased biocatalytic solar-to-chemical conversion by $\mathrm{FeOOH} / \mathrm{BiVO}_{4} /$ perovskite tandem structure. Nat. Commun. 9, 4208 (2018).

Kim, J. et al. Biocatalytic $\mathrm{C}=\mathrm{C}$ Bond Reduction through Carbon Nanodot-Sensitized Regeneration of NADH Analogues. Angew. Chem. Int. Ed. 57, 13825-13828 (2018). Huang, Z. et al. Enhanced photocatalytic alkane production from fatty acid decarboxylation via inhibition of radical oligomerization. Nat. Catal. 3, 170-178 (2020). Creel, E. B. \& McCloskey, B. D. Scalable $\mathrm{CO}_{2}$-to-oxygenate production. Nat. Catal. 1, 6-7 (2018).

Hisatomi, T. \& Domen, K. Reaction systems for solar hydrogen production via water splitting with particulate semiconductor photocatalysts. Nat. Catal. 2, 387-399 (2019).

Lin, L. et al. Molecular-level insights on the reactive facet of carbon nitride single crystals photocatalysing overall water splitting. Nat. Catal. 3, 649-655 (2020).

Ulmer, U. et al. Fundamentals and applications of photocatalytic $\mathrm{CO}_{2}$ methanation. Nat. Commun. 10, 3169 (2019).

Wang, D., Lee, S. H., Kim, J. \& Park, C. B. "Waste to Wealth": Lignin as a Renewable Building Block for Energy Harvesting/Storage and Environmental Remediation. ChemSusChem 13, 2807-2827 (2020).

Chen, C.-C., Dai, L., Ma, L. \& Guo, R.-T. Enzymatic degradation of plant biomass and synthetic polymers. Nat. Rev. Chem. 4, 114-126 (2020).

Wang, M. \& Wang, F. Catalytic Scissoring of Lignin into Aryl Monomers. Adv. Mater. 31, 1901866 (2019).

Li, C., Zhao, X., Wang, A., Huber, G. W. \& Zhang, T. Catalytic Transformation of Lignin for the Production of Chemicals and Fuels. Chem. Rev. 115, 11559-11624 (2015).

Sanderson, K. Lignocellulose: A chewy problem. Nature 474, S12-S14 (2011).

Wang, D. et al. Lignin-fueled photoelectrochemical platform for light-driven redox biotransformation. Green Chem. 22, 5151-5160 (2020). 
Romero, N. A. \& Nicewicz, D. A. Organic Photoredox Catalysis. Chem. Rev. 116, 1007510166 (2016).

328 Zhang, G., Lan, Z.-A. \& Wang, X. Conjugated Polymers: Catalysts for Photocatalytic Hydrogen Evolution. Angew. Chem. Int. Ed. 55, 15712-15727 (2016).

Boehm, A. M., Wieser, J., Butrouna, K. \& Graham, K. R. A new photon source for ultraviolet photoelectron spectroscopy of organic and other damage-prone materials. Org. Electron. 41, 916 (2017).

Koppenol, W. H., Stanbury, D. M. \& Bounds, P. L. Electrode potentials of partially reduced oxygen species, from dioxygen to water. Free Radical Biol. Med. 49, 317-322 (2010).

Sadeghifar, H. \& Ragauskas, A. Lignin as a UV Light Blocker-A Review. Polymers 12, 1134 (2020).

Hou, H., Zeng, X. \& Zhang, X. Production of Hydrogen Peroxide by Photocatalytic Processes. Angew. Chem. Int. Ed., doi:10.1002/anie.201911609 (2020). Yoon, J. et al. Piezobiocatalysis: Ultrasound-Driven Enzymatic Oxyfunctionalization of $\mathrm{C}-\mathrm{H}$ Bonds. ACS Catal. 10, 5236-5242 (2020). Science 343, 1239176 (2014).

Choi, D. S. et al. Photoelectroenzymatic Oxyfunctionalization on Flavin-Hybridized Carbon Nanotube Electrode Platform. ACS Catal. 7, 1563-1567 (2017).

6 Zhao, J., Nanjo, T., de Lucca, E. C. \& White, M. C. Chemoselective methylene oxidation in aromatic molecules. Nat. Chem. 11, 213-221 (2019).

7 Simon, T. et al. Redox shuttle mechanism enhances photocatalytic $\mathrm{H}_{2}$ generation on Nidecorated CdS nanorods. Nat. Mater. 13, 1013-1018 (2014).

8 Huang, C. et al. Unveiling the Structural Properties of Lignin-Carbohydrate Complexes in Bamboo Residues and Its Functionality as Antioxidants and Immunostimulants. ACS Sustainable Chem. Eng. 6, 12522-12531 (2018).

30 

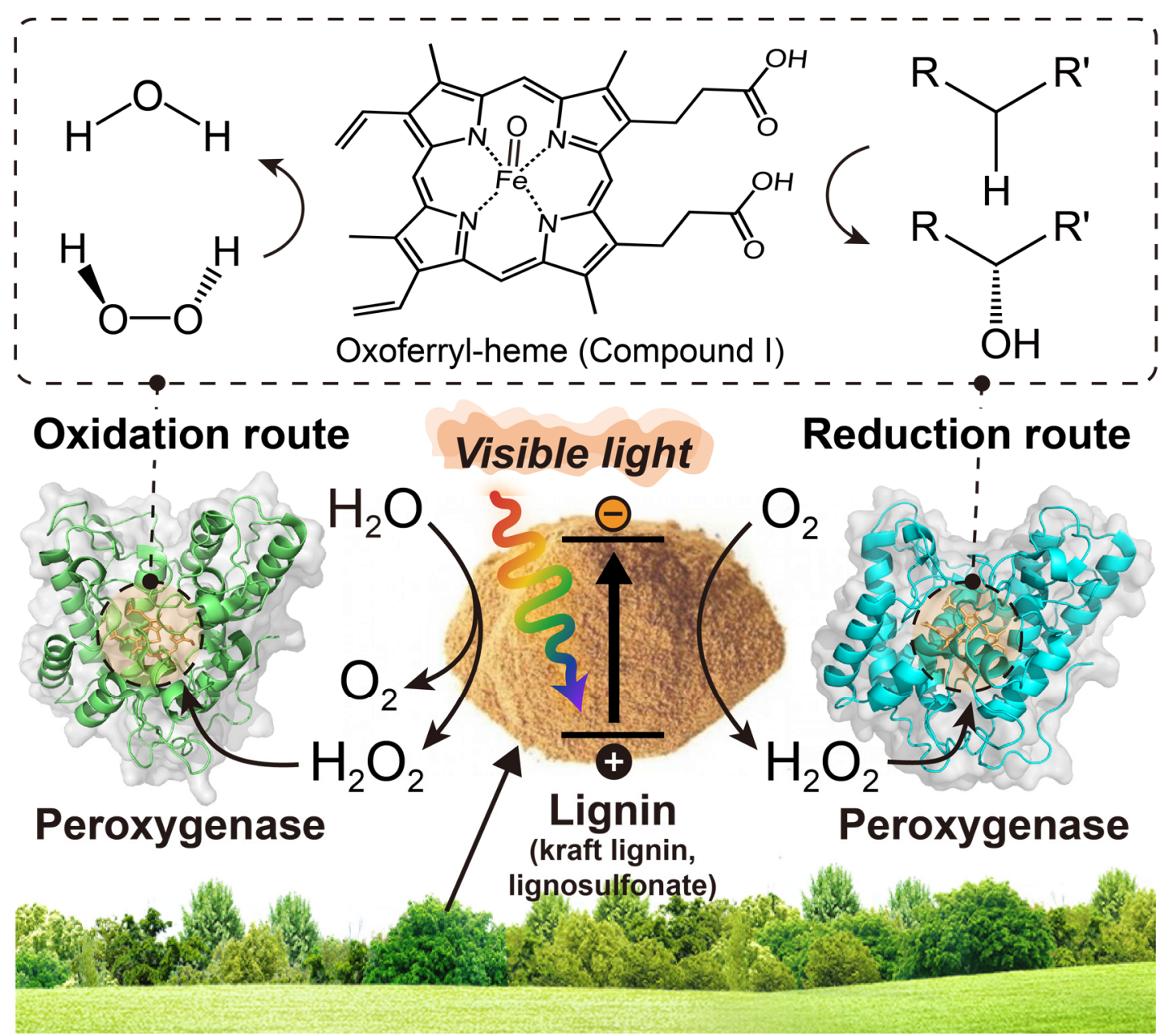

2 Fig. 1: Illustration of a photoenzymatic oxyfunctionalization reaction through the 3 synergetic integration of lignin photocatalysts and peroxygenase redox biocatalysts.

4 Photoactivation of lignin energy materials (e.g., lignosulfonate and kraft lignin) under visible 5 light drives redox reactions, such as (i) reduction of $\mathrm{O}_{2}$ to $\mathrm{H}_{2} \mathrm{O}_{2}$ and (ii) oxidation of $\mathrm{H}_{2} \mathrm{O}$ to $6 \quad \mathrm{H}_{2} \mathrm{O}_{2}$ and $\mathrm{O}_{2}$. The in situ generated $\mathrm{H}_{2} \mathrm{O}_{2}$ activates oxoferryl-heme (Compound I, redox center) 7 of peroxygenases to catalyze stereoselective oxyfunctionalization reactions (e.g., hydroxylation 8 and epoxidation). 


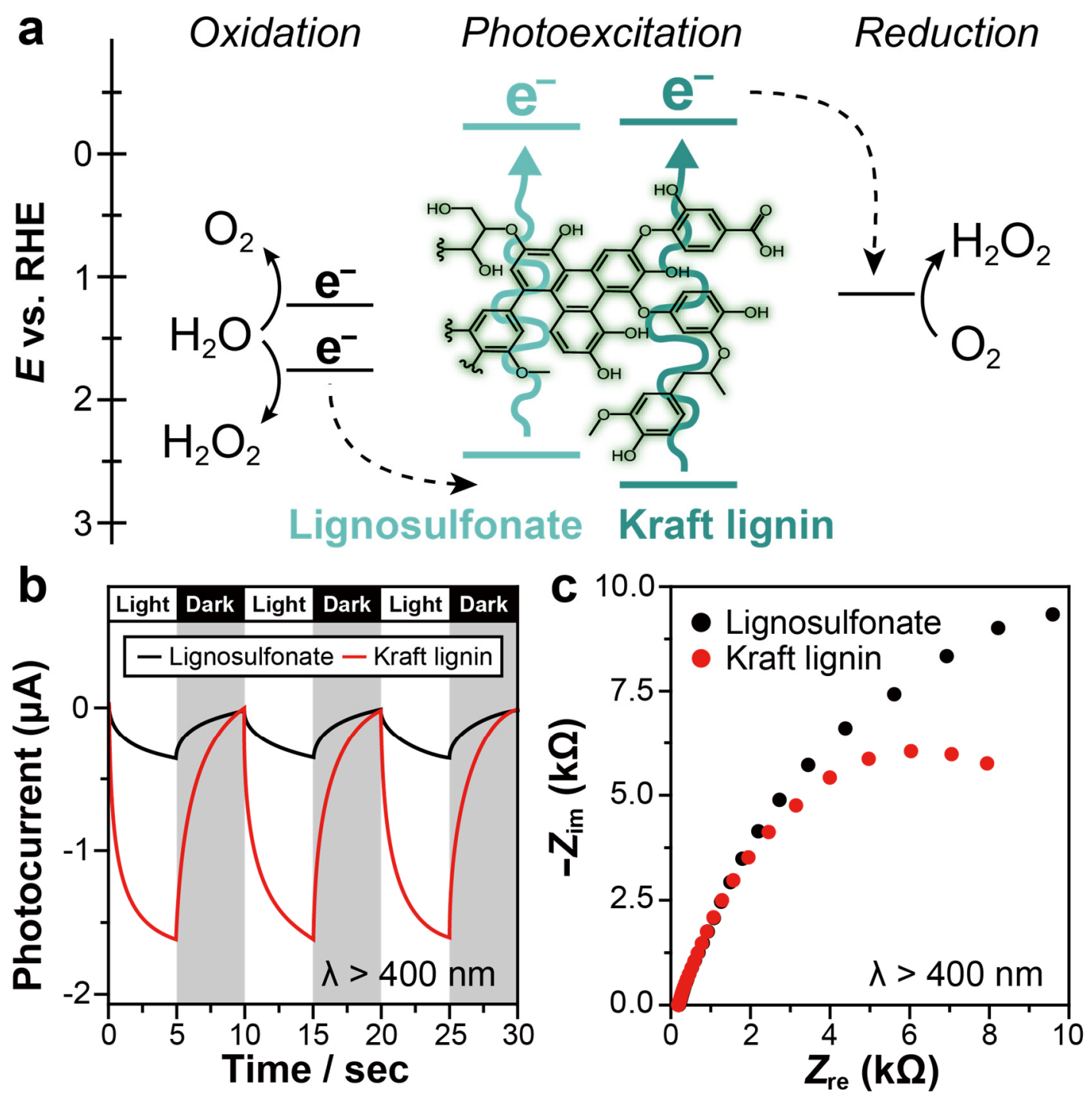

Fig. 2: Electronic and photophysical properties of lignin photocatalysts. (a) Energy diagram for lignin-sensitized $\mathrm{O}_{2}$ reduction to $\mathrm{H}_{2} \mathrm{O}_{2}$ and $\mathrm{H}_{2} \mathrm{O}$ oxidation to $\mathrm{H}_{2} \mathrm{O}_{2}$ and $\mathrm{O}_{2}$. (b) Transient photocurrent response of lignin photocatalysts at -0.028 VRHE under solar-simulated visible light. (c) Electrochemical impedance spectroscopic analysis in the form of Nyquist plots under visible light at $-0.028 \mathrm{~V}_{\mathrm{RHE}}$. $Z_{\mathrm{re}}$ and $Z_{\mathrm{im}}$ indicate real and imaginary impedance, respectively. Light source: xenon lamp $\left(\lambda>400 \mathrm{~nm}\right.$, photon flux: $\left.0.58 \mu \mathrm{E} \mathrm{cm}^{-2} \mathrm{~s}^{-1}\right)$. 

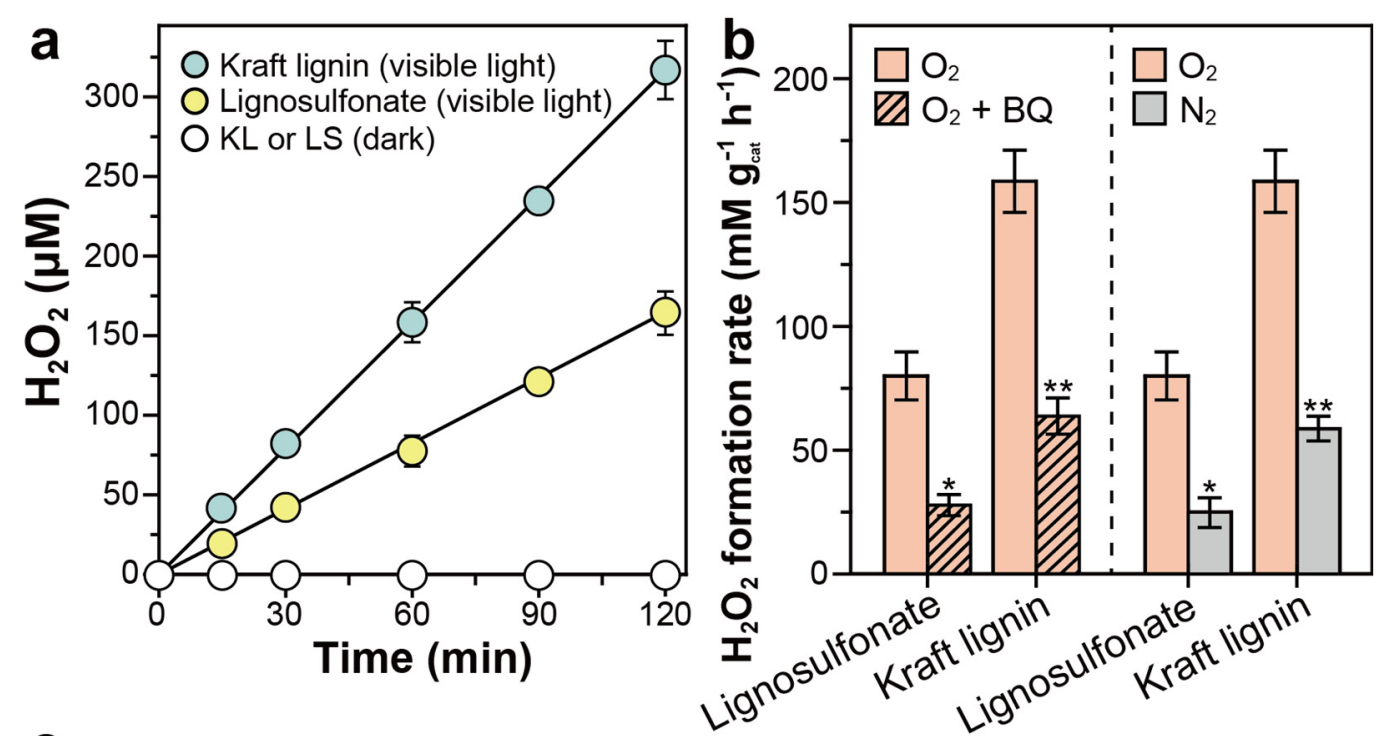

C

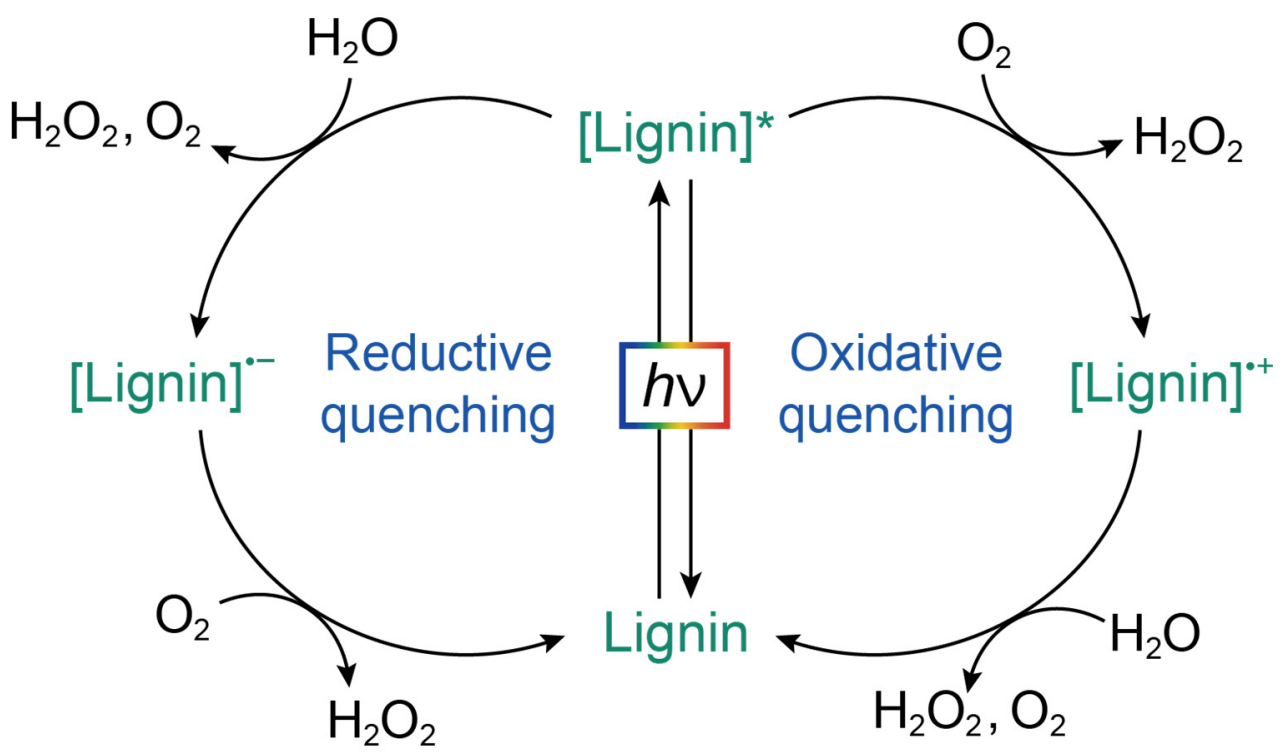

Fig. 3: Lignin-sensitized production of $\mathrm{H}_{2} \mathrm{O}_{2}$ under visible light and its mechanism study.

3 (a) Visible light-driven generation of $\mathrm{H}_{2} \mathrm{O}_{2}$ by lignin photocatalysts. Reaction conditions: $1 \mathrm{mg}$ $4 \mathrm{~mL}^{-1}$ lignin photocatalyst in an $\mathrm{O}_{2}$-enriched $\mathrm{KPi}$ buffer $(100 \mathrm{mM}, \mathrm{pH} 7.0)$ under dark or light 5 conditions $\left(\lambda>400 \mathrm{~nm}\right.$, photon flux: $\left.0.58 \mu \mathrm{E} \mathrm{cm}^{-2} \mathrm{~s}^{-1}\right)$ at $298.15 \mathrm{~K}$. (b) Effect of 1,46 benzoquinone (left panel) or $\mathrm{N}_{2}$ (right panel) on lignin-sensitized $\mathrm{H}_{2} \mathrm{O}_{2}$ production. Reaction 7 conditions: $1 \mathrm{mg} \mathrm{mL}^{-1}$ lignin photocatalyst and $1 \mathrm{mM} \mathrm{p}$-benzoquinone in a KPi solution (100 $8 \mathrm{mM}, \mathrm{pH} 7.0)$ at $298.15 \mathrm{~K}$. Error bars correspond to the standard deviation $(n=3)$. Single and 9 double asterisks ( $*$ and $* *$ ) denote two groups, the difference of which was statistically 10 insignificant. (c) Two possible photocatalytic pathways of lignin-sensitized formation of $\mathrm{H}_{2} \mathrm{O}_{2}$ 11 and $\mathrm{O}_{2}$. 
Table 1: Substrate scope of photobiocatalytic oxyfunctionalization reaction using lignin photocatalysts and $\mathrm{r}$ AaeUPO biocatalysts.

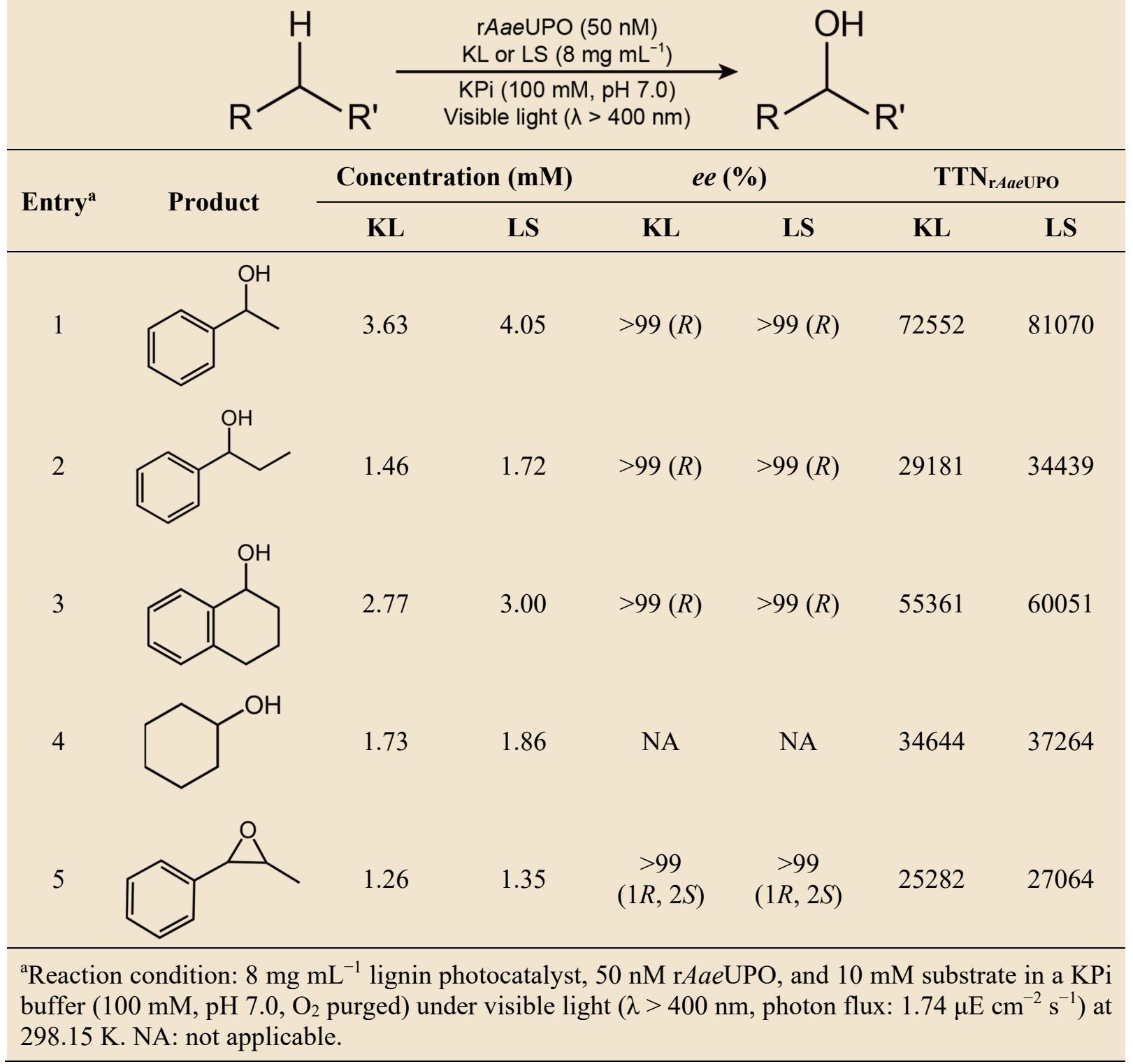




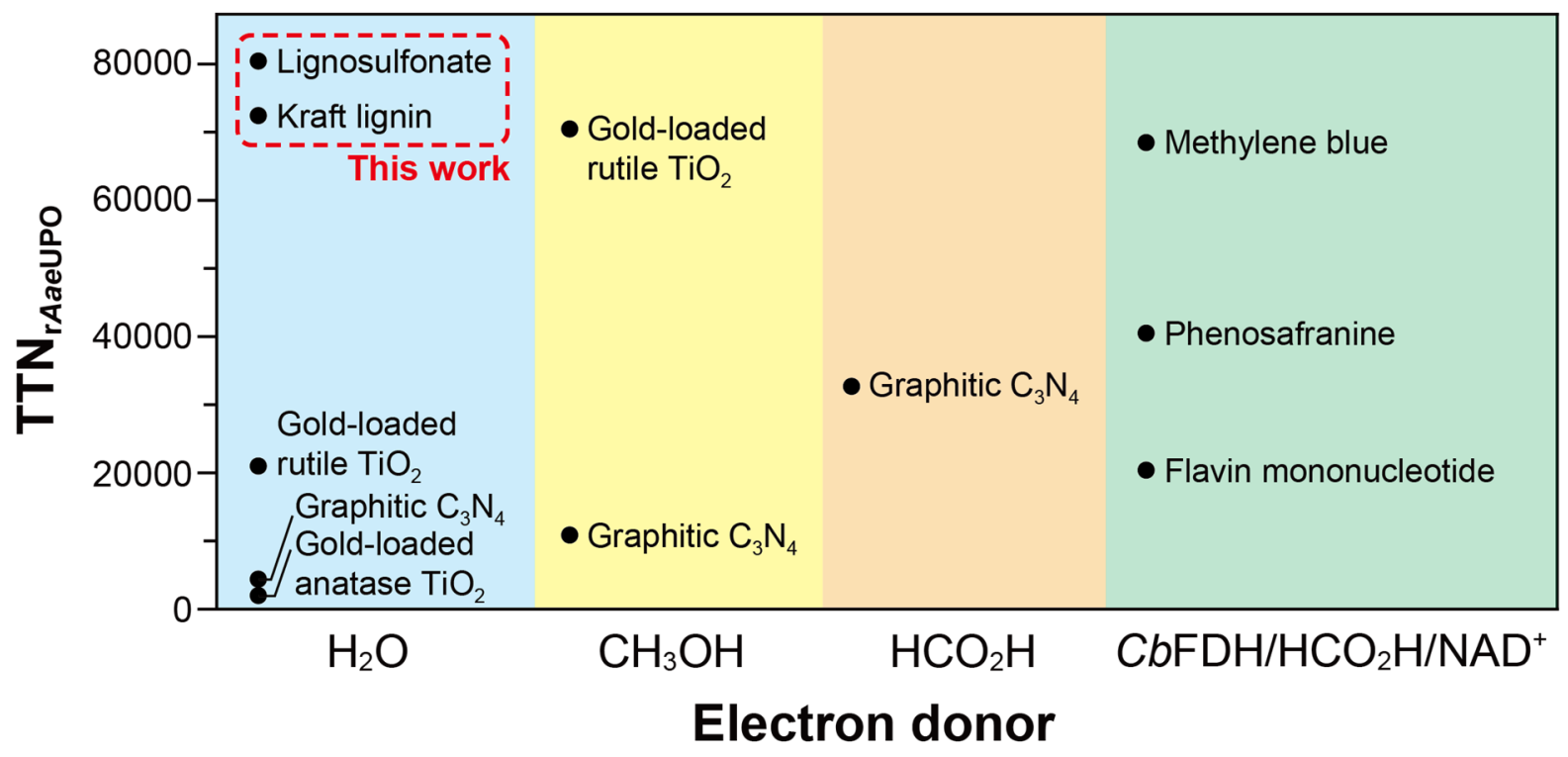

Fig. 4: Comparison of total turnover numbers of state-of-the-art photoenzymatic systems that use rAaeUPO catalysts and visible light for ethylbenzene hydroxylation.

5 References: gold-loaded rutile $\mathrm{TiO}_{2}$ nanoparticle ${ }^{3,4}$, gold-loaded anatase $\mathrm{TiO}_{2}$ nanoparticle ${ }^{3}$,

6 graphitic carbon nitride ${ }^{8}$, methylene blue ${ }^{7}$, phenosafranine ${ }^{7}$, and flavin mononucleotide ${ }^{7}$.

$7 \quad \mathrm{CbFDH}$ : formate dehydrogenase from Candida boidinii. 